\title{
Aortic Valve Atresia
}

National Cancer Institute

\section{Source}

National Cancer Institute. Aortic Valve Atresia. NCI Thesaurus. Code C98818.

A rare congenital heart defect characterized by the complete failure of the aortic valve to open. It is manifested during infancy with cyanosis, dyspnea, and rapidly progressing heart failure. 